\title{
Molecular mechanisms of astragaloside-IV in cancer therapy (Review)
}

\author{
TIANQI CHEN, PEIYING YANG and YINGJIE JIA \\ Department of Oncology, First Teaching Hospital of Tianjin University of \\ Traditional Chinese Medicine, Tianjin 300380, P.R. China
}

Received June 12, 2020; Accepted December 23, 2020

DOI: $10.3892 / \mathrm{ijmm} .2021 .4846$

\begin{abstract}
Radix Astragali (RA) is widely used in traditional Chinese medicine (TCM), and astragaloside IV (AS-IV) is the most critical component of RA. Previous studies have demonstrated that AS-IV exerts effects on the myocardium, nervous system and endocrine system, among others. In the present review article, data from studies conducted over the past 20 years were collated, which have evaluated the effects of AS-IV on tumors. The mechanisms of action of AS-IV on malignant cells both in vivo and in vitro were summarized and it was demonstrated that AS-IV plays a vital role, particularly in inhibiting tumor growth and metastasis, promoting the apoptosis of tumor cells, enhancing immune function and preventing drug resistance. Moreover, AS-IV controls several epithelial-mesenchymal transformation (EMT)-related and autophagy-related pathways, such as the phosphoinositide-3-kinase (PI3K)/protein kinase $\mathrm{B}$ $(\mathrm{AKT}), \mathrm{Wnt} / \beta$-catenin, mitogen-activated protein kinase (MAPK)/extracellular regulated protein kinase (ERK) and transforming growth factor- $\beta$ (TGF- $\beta$ )/SMAD signaling pathways, which are commonly affected in the majority of tumors. The present review provides new perspectives on the functions of AS-IV and its role as an adjuvant treatment in cancer chemotherapy.
\end{abstract}

\section{Contents}

1. Introduction

2. Literature search

3. Effects of AS-IV in cancer models

4. Conclusions and future perspectives

Correspondence to: Professor Yingjie Jia, Department of Oncology, First Teaching Hospital of Tianjin University of Traditional Chinese Medicine, 88 Changling Road, Xiqing, Tianjin 300380, P.R. China

E-mail: bchen@casit.com.cn

Key words: astragaloside IV, epithelial-mesenchymal transformation, cancer, molecular mechanisms, chemosensitivity

\section{Introduction}

Cancer is the second leading cause of mortality worldwide and results in an increasing number of deaths annually. The World Health Organization postulates a $60 \%$ increase in cancer cases over the next 20 years globally (1). The medical treatment of the majority of cancers almost always involves several traditional approaches, such as surgery, chemotherapy and radiotherapy. Surgical resection is a suitable approach for tumor management in the early stages of primary tumors. However, surgery is still limited by post-operative recurrence and metastasis $(2,3)$. Of late, chemoradiotherapy, molecular targeted therapy and immune checkpoint inhibitors have been considered the treatment approach for advanced stages of cancers; however, severe adverse events limit their use $(4,5)$. Therefore, alternative therapeutic methods are required to address these existing shortcomings. Accordingly, traditional Chinese medicines (TCMs), such as ginseng, Radix Astragali (RA), Scutellaria barbata, Curcumae and turmeric, are used to enhance the efficacy and reduce the side-effects of chemoradiotherapy. TCMs are effective in suppressing tumor progression, relieving surgery-associated discomfort, improving immune function and preventing complications caused by the use of other treatment modalities (6).

RA is a dietary complement widely used in TCM and is known to modulate the immune system and attenuate the adverse effects of cytotoxic agents (7). Saponins are the primary constituents that are responsible for the suppression of tumor growth, which exert their effects via intrinsic and extrinsic apoptotic pathways, modulating intracellular signaling pathways, and inhibiting metastasis and angiogenesis. Astragaloside IV (AS-IV; chemical structure presented in Fig. 1) and astragaloside II are the 2 main components of RA (8).

AS-IV, chemically known as 3-O- $\beta$-D-xylopyranosyl6-O- $\beta$-D-glucopyranosyl-cycloastragenol $\left(\mathrm{C}_{14} \mathrm{H}_{68} \mathrm{O}_{14}\right)$, is a lanolin-alcohol type of tetracyclic triterpenoid saponin. It is included in the Chinese and European Pharmacopoeia as a quality-control indicator of RA. It has long been used since ancient times in China without any evident hepatotoxic and nephrotoxic effects. Moreover, no side-effects have been reported in rats following 14 weeks of the continuous oral administration of AS-IV (10 mg/kg/day) $(9,10)$. However, there is currently no data available regarding the safety of AS-IV in 
humans, at least to the best of our knowledge. The methods used to extract AS-IV include ultrafiltration, high-speed centrifugation, ultrasonic extraction and alcohol precipitation. The present review article aimed to obtain and collate data from studies conducted over the past 20 years on the effects of AS-IV on tumors. In addition, the mechanisms of action of AS-IV on malignant cells both in vivo and in vitro are summarized in order to provide insight into the effects of AS-IV on cancer in humans.

\section{Literature search}

Search strategy. Studies in English and Chinese, as well as trials published before June 1, 2020, were searched on online databases. The databases in the English language that were used were PubMed, MEDLINE, Embase, ScienceDirect, Web of Science, BIOSIS Previews and the Cochrane Library and Cochrane Central Register of Controlled Trials (CENTRAL). The Chinese databases used for the searches included the China National Knowledge Infrastructure (CNKI) database and Wanfang Med Online.

In the present review, 'astragaloside IV', 'Cancer' and 'mechanism' were used as the key search concepts. Additionally, their synonyms were also included. Moreover, manual searches were also carried out using the aforementioned terms. The search methodology is described as follows as an example: i) astragaloside IV; ii) astraloside; iii) ASIV; iv) i OR ii OR iii; v) cancer[MeSH]; vi) tumor[MeSH]; vii) v OR vi; viii) pathway[MeSH]; ix) mechanism[MeSH]; x) viii OR ix; and xi) iv AND vii AND ix.

Inclusion criteria. The inclusion criteria were as follows: Studies exploring the molecular mechanisms of AS-IV in cancer; studies with comparable experimental and control groups, and those that successfully established animal models of cancer; studies in which animal experiments were approved by an ethics committee; and studies that investigated related pathways involving upstream and downstream molecular mechanisms and published experimental findings, which could be retrieved.

Exclusion criteria. The exclusion criteria were as follows: Studies that included only AS-IV or astragalus polysaccharide (APS) as the experimental group; studies that had an obvious risk of bias, including selection bias, performance bias, detection bias, reporting bias and attrition bias; case studies, cross-over studies and studies without a separate control group; studies combining AS-IV with other TCM interventions, in which data specific to the effect of AS-IV interventions on cancer could not be extracted separately.

\section{Effects of AS-IV in cancer models}

AS-IV has been widely used in the management of cardiovascular, digestive, endocrine, and nerve-related diseases (11-13). Furthermore, it exerts significant anticancer effects when used alone or as an adjuvant to other treatment modalities, as it sensitizes the host to other drugs (Table I).

To the best of our knowledge, there are no systematic reviews available that discuss the role of AS-IV in cancer; therefore, in the present review article, the efficacy and mechanisms of action of AS-IV in cancer therapy are presented and discussed.

Induction of apoptosis. Apoptosis, also known as programmed cell death, includes the initiation stage, effect stage and degradation stage. Apoptosis is characterized by surface blebbing, chromatin condensation, fragmentation of chromosomal DNA and the appearance of apoptotic bodies.

As shown in Table I and Fig. 2, AS-IV leads to apoptosis mainly by the mitochondrial-dependent intrinsic pathway and the death receptor-dependent extrinsic pathway. The intrinsic pathway leads to the release of cytochrome $c$ (Cyt C) from the mitochondria, which activates caspase-9, -3 and -7 (14). However, Bcl-2 can inhibit the release of Cyt $\mathrm{C}$ and avoid the intrinsic apoptosis induced by Bax (15). Research has indicated that AS-IV can enhance the $\mathrm{Bax} / \mathrm{Bcl}-2$ ratio to induce intrinsic apoptosis in a number of types of cancer, including colorectal cancer (CRC), breast cancer, lung cancer, vulvar squamous cell cancer (VSCC) and hepatocellular carcinoma (HCC) (16-21).

In terms of extrinsic apoptosis, certain receptors, e.g., the Fas ligands and tumor necrosis factor (TNF)- $\alpha$, can set off the caspase-8-dependent extrinsic apoptotic pathways and become activated following the caspase cascade, which finally triggers apoptosis (22). It has been reported that combined treatment with AS-IV and cisplatin $(10 \mu \mathrm{M})$ markedly promotes the cleavage of caspase- 8 and -3 , and poly(ADP-ribose) polymerase (PARP) in MG-63 and 143B cells via the Fas/FasL signaling pathway, which considerably sensitizes the osteosarcoma cells to the effects of cisplatin (23). In CRC, AS-IV alone can increase the release of $\mathrm{Cyt} C$ into the cytoplasm and upregulate the $\mathrm{Bax} / \mathrm{Bcl}-2$ ratio, as well as activate PARP and the caspase cascade (16).

The IAP protein family may be the most important apoptotic regulator involved in both intrinsic and extrinsic apoptosis pathways, including the x-linked mammalian inhibitor of apoptosis (XIAP), survivin and cellular inhibitor of apoptosis protein 1 (cIAP1) $(22,24)$.

$\mathrm{HCC}$ is associated with a high morbidity and mortality rate globally, and presents with increased levels of anti-apoptotic proteins, including myeloid cell leukemia 1 (MCL1), cellular FLICE-like inhibitory protein (c-FLIP) and XIAP. c-FLIP can suppress death receptor-mediated apoptosis, which inhibits caspase-8 (25-28). Additionally, studies have demonstrated that MCL1 can block apoptosis induced by various apoptotic stimuli, including chemoradiotherapy (29-31). Its high protein expression levels in cancer cells are associated with drug resistance (32). AS-IV has been shown to significantly decrease XIAP, MCL1, c-FLIP and survivin expression in HCC and C6 glioma cells $(33,34)$.

Inhibition of proliferation. High levels of reactive oxygen species (ROS) are considered to be a driver of a number of diseases, such as cancer and neurodegeneration. ROS are capable of increasing the carcinogenic potential of cancer cells and activating hypoxia-inducing factor (HIF) in hypoxic tumor cells to maintain cell viability $(32,35)$. On the other hand, cells are capable of eliminating surplus ROS via mechanisms involving superoxide dismutase (SOD) and glutathione 


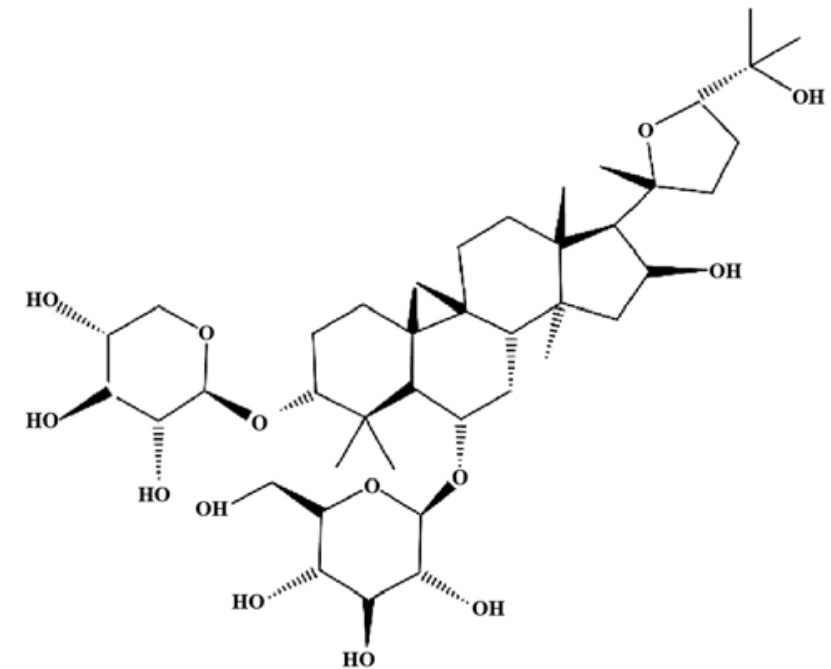

Figure 1. Chemical structure of astragaloside IV.

peroxidase (GSH-Px) (36). Yang proved that AS-IV interrupted the proliferation of Spc-A-1 cells and suggested that the mechanism was related to the activity of the antioxidant enzymes, SOD and GSH-Px, which modulate ROS levels in cancer (37).

In the B7/cluster of differentiation (CD)28 superfamily, the overexpression of $\mathrm{B} 7-\mathrm{H} 3$ is observed in various types of cancer. It can downregulate the T-cell-mediated immune responses, leading to immune escape (38-40). AS-IV can reduce $\mathrm{B} 7-\mathrm{H} 3$ by upregulating miR-29c, which inhibits cell growth and reduces the protein level of the cell-cycle regulators, cyclin D1 and CDK4, in CRC cells. Thus, the anticancer effects of AS-IV may be mediated via the B7-H3/nuclear factor (NF)- $\mathrm{kB} /$ cyclin D1 axis (41). It also increases the cytotoxicity of cisplatin in non-small cell lung cancer (NSCLC) by suppressing the expression of B7-H3 (42). Moreover, another study reported that AS-IV inhibited the proliferation of HCC HepG2 cells and promoted apoptosis by regulating oxidative stress and the NF- $\mathrm{kB}$ signaling pathway (43).

Inhibition of metastasis. Matrix metalloproteinases (MMPs) are a group of proteolytic enzymes containing active $\mathrm{Zn}^{2+}$. Its functions include, but are not limited to, degrading the extracellular matrix (ECM). The interaction between MMPs and cell-surface ECM receptors affects the function of integrins and contributes to cell invasion (44). MMP-2 and MMP-9, in particular, have been considered to play a vital role in tumor progression (45).

The extracellular signal-regulated kinase pathway (ERK), an important upstream switch, has been known to regulate the secretion of MMPs in cells (46). Mitogen-activated extracellular signal-regulated kinase (MAPK) is a serine/threonine (Ser/Thr) kinase involved in cell proliferation, differentiation, growth and apoptosis. In general, the MAPK/ERK pathway, i.e., Ras-Raf-MEK-ERK pathway, is deregulated in various types of cancers (47). Recently, inhibitors against the MAPK/ERK pathway have been designed to combat glioma and have been shown to be effective in the U251, as well as the SGC7901 cell lines with the downregulation of the expression of MMP-2 and MMP-9 (48-52). Li et al and Cao reported that AS-IV inhibited the progression of glioma and gastric cancer by interfering with the MAPK/ERK signaling pathway $(53,54)$. Moreover, ascites in H22-tumor-bearing mice have been shown to be decreased by AS-IV by inhibiting the angiogenesis- and metastasis-associated genes, as well as the expression of aquaporins (AQPs) (55).

Tissue inhibitors of metalloproteinases (TIMPs) comprise TIMP-1, TIMP-2, TIMP-3 and TIMP-4, all of which can form complexes with several MMPs via covalent bonds, thereby inhibiting MMPs $(56,57)$. The NM23 gene is a widely studied metastasis suppressor gene. The protein encoded by NM23 has the function of inhibiting tumor metastasis (58). AS-IV can downregulate the mRNA and protein expression of MMP-2, -7 and -9 , can mediate multidrug resistance/P-glycoproteins (MDR1/P-gp) and multidrug resistance-associated protein 1(MRP-1), and upregulate TIMP-1 and NM23 to inhibit the proliferation of BGC823 (gastric cancer) cells and reverse drug resistance (59).

Epithelial-mesenchymal transformation (EMT) is the conversion of a polarized epithelial cell, which interacts with the basement membrane by means of its basal surface, to a mesenchymal cell. As regards the metastatic process, EMT can be detected based on specific molecular changes, such as diminished E-cadherin and cytokeratin levels, and elevated levels of $\mathrm{N}$-cadherin and vimentin (60). As the transforming growth factor $\beta 1$ (TGF- $\beta 1$ ) is a known factor in triggering the initiation and execution of EMT, the downregulation of TGF- $\beta 1$ signaling can prevent EMT in tumor cells. As shown in Fig. 3, AS-IV can affect EMT via several pathways.

The Wnt/ $\beta$-catenin signaling pathway regulates EMT. Using U251 cells, Han et al found that AS-IV treatment inhibited TGF- $\beta 1$-guided EMT by interrupting the Wnt/ $\beta$-catenin pathway (61). $\beta$-catenin can also modulate glycogen synthase kinase $3 \beta$ (GSK3 3 ). AKT is an upstream molecule that activates GSK $3 \beta$ phosphorylation, eventually leading to the accumulation of $\beta$-catenin in the cell nucleus (62). AS-IV has also been shown to attenuate EMT in HCC and NSCLC via the modulation of the Akt/GSK-3 $\beta / \beta$-catenin pathway $(18,63)$.

Phosphoinositide-3-kinase/protein kinase B/nuclear factor $\kappa \mathrm{B}(\mathrm{PI} 3 \mathrm{~K} / \mathrm{Akt} / \mathrm{NF}-\kappa \mathrm{B})$ is another common pathway suppressing TGF- $\beta 1$-induced EMT. It has been reported that AS-IV can inhibit TGF- $\beta 1$-induced EMT by interfering with the PI3K/Akt/NF- $\kappa \mathrm{B}$ signaling pathway in $\mathrm{SiHa}$ and MGC-803 cells $(21,64)$. Moreover, it inhibits the phosphorylation of MAPK and mTOR to varying degrees, which is related to the proliferation of cancer cells.

Apart from the signaling pathways discussed, AS-IV may also interrupt the migration and invasion of A549 cells. This process is associated with the suppression of PKC- $\alpha$-ERK1/2-NF- $\kappa B$ and can be detected based on specific proteins, e.g., E-cadherin, integrin $\beta 1$ and MMPs (65). PKC- $\alpha$ expression can be affected by ROS, which can induce the downstream signaling of ERK1/2 and activate NF- $\mathrm{KB}$ to initiate the metastasis of carcinoma cells (66).

In parallel, several miRNAs take part in the inhibition of EMT signaling (67). For example, miR-134 from the miRNA gene family has been proven to inhibit EMT $(68,69)$. CREB1 is an important transcription enhancer. A previous study reported that miR-134 activated by AS-IV markedly inhibiting EMT signaling and increasing the chemosensitivity of SW-480 cells to oxaliplatin by inhibiting CREB1 expression (70). 


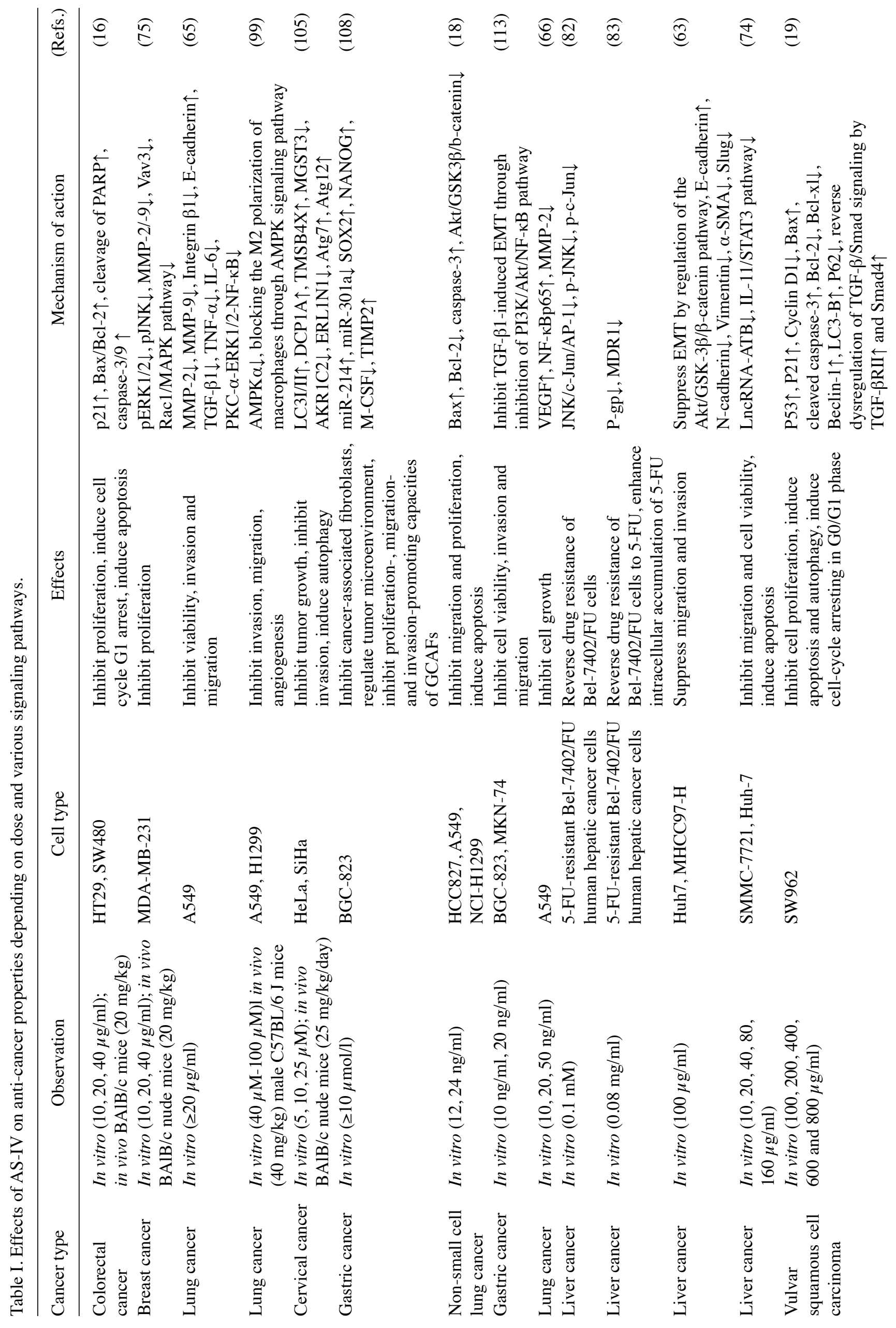




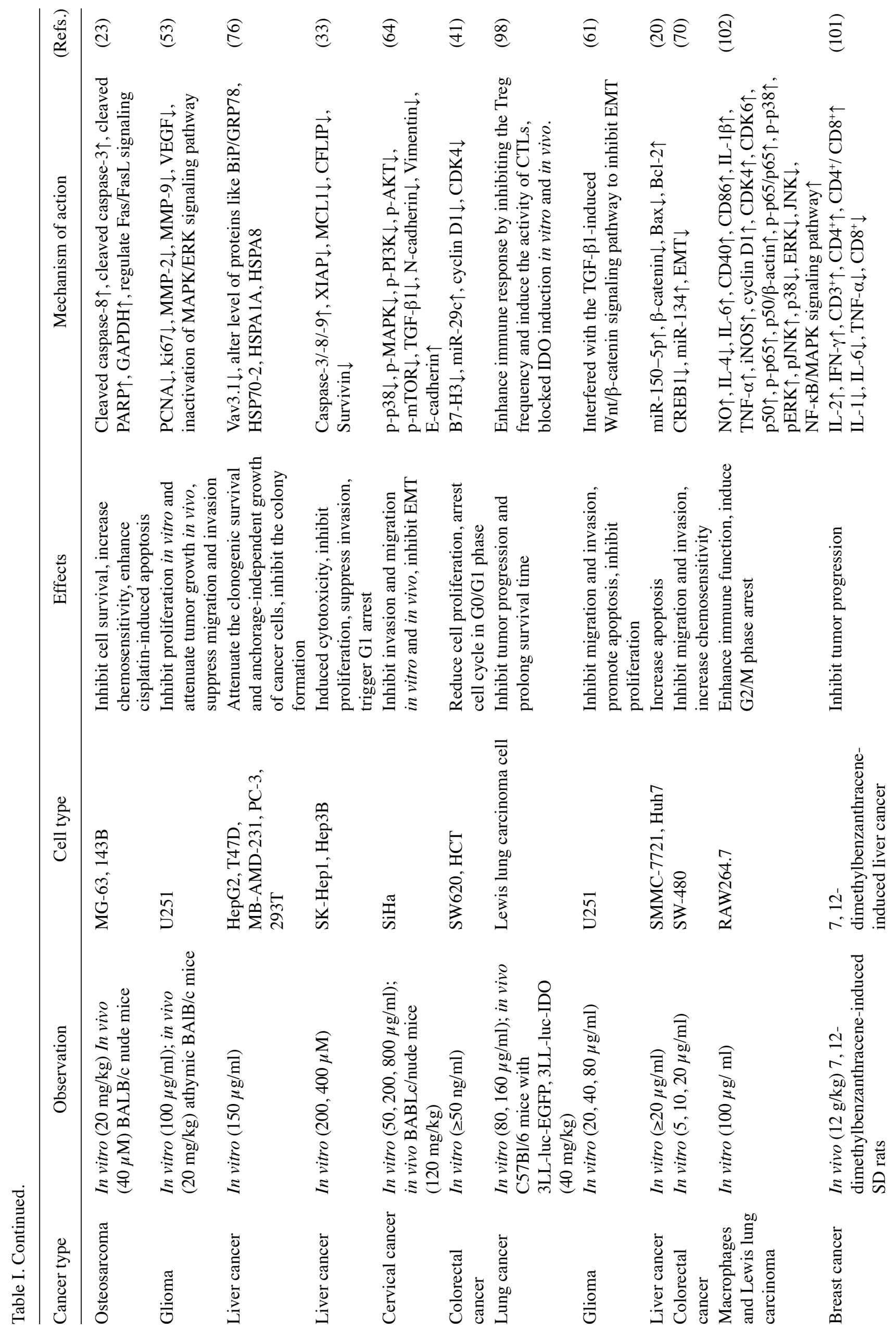




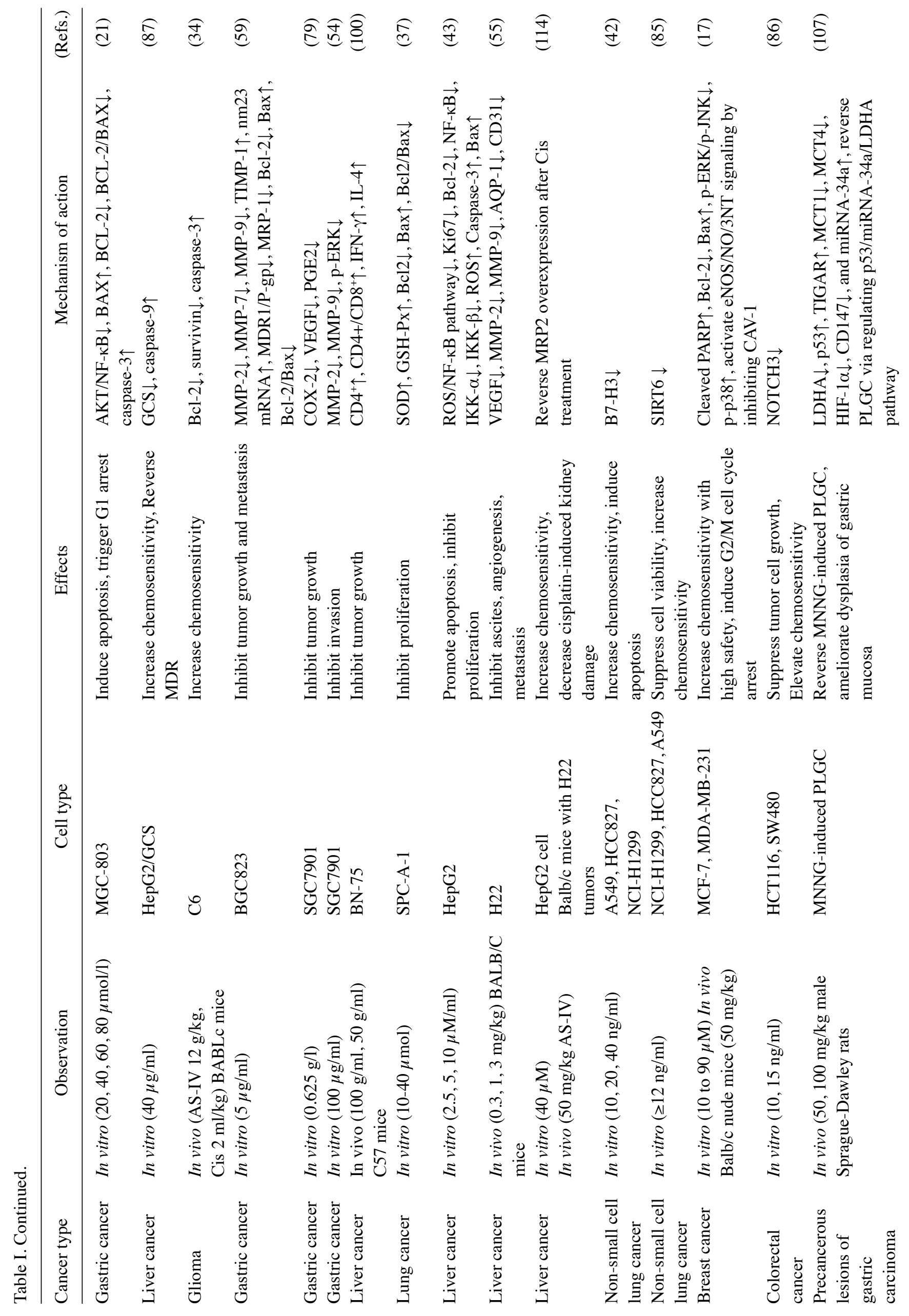




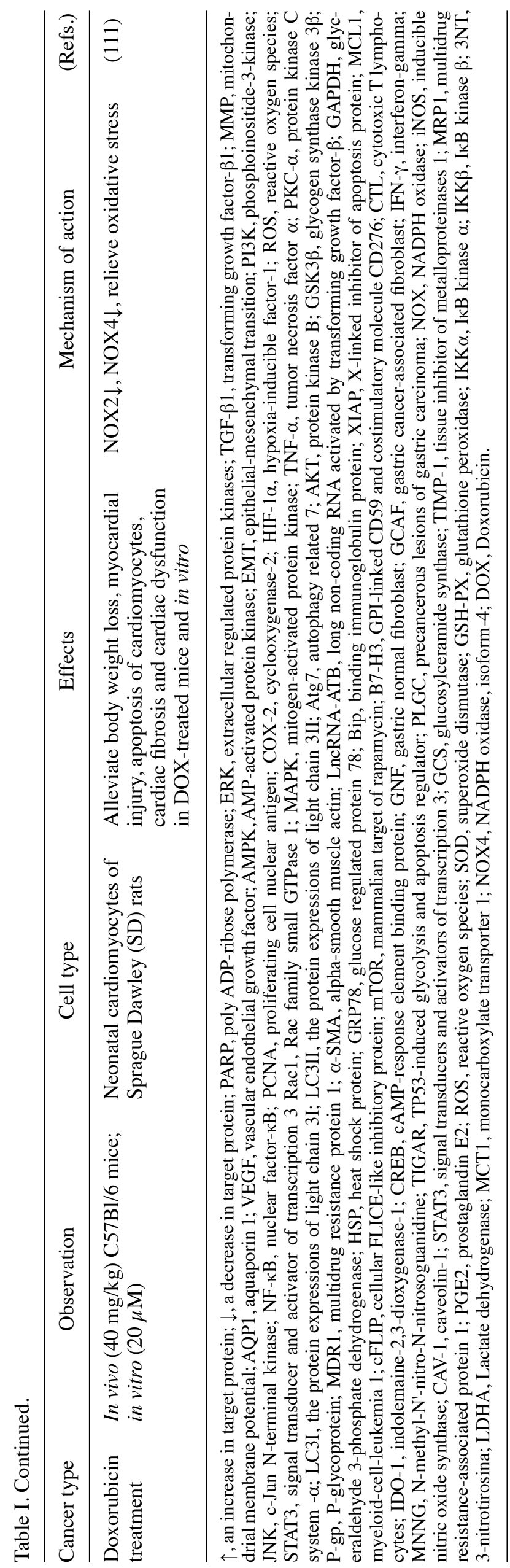

Similar to miR-134, miR-150-5p markedly downregulates $\beta$-catenin in liver carcinoma, functioning as an inhibitor to attenuate the proliferation of cancer cells. It has been well-established that AS-IV can regulate the miR150-5p/ $\beta$-catenin axis to induce the apoptosis of HCC cells (20).

Long non-coding RNAs (lncRNAs) are long nucleotide chains without protein-coding capability $(71,72)$. LncRNAs have been identified to participate in several biological processes and are known to play a crucial role in the emergence and progression of cancers. For example, lncRNA-ATB promotes EMT by connecting to the miR-200 family, maintaining the viability of malignant cells via IL-11/STAT3 signaling, which can be prevented by AS-IV $(73,74)$.

Vav3, a member of the Vav protein family, functions as an exchange factor for Rho family GTPases, such as Rac1. It consists of 8 domains, and the complexity of the structure contributes to its various functions. Vav3 modulates different members in the Rho family to participate in the MAPK, $\mathrm{PI} 3 \mathrm{~K} / \mathrm{Akt}$ and NF- $\mathrm{KB}$ signaling pathways. Previous studies have demonstrated that MMPs and Rho GTPases play a pivotal role in the migration of the majority of malignant cells. AS-IV has been shown to have antitumor and anti-metastasis functions both in vivo and in vitro. These functions are accomplished by the downregulation of Vav3 in liver and breast cancer by blocking the Rac1/MAPK signaling pathway, as well as by decreasing MMP-2, MMP-9, and the proteins related to cellular responses during stress and cell signaling $(75,76)$.

Inhibition of angiogenesis. Neovascularization relies on the secretion of vascular endothelial growth factor (VEGF) by tumor cells and the proliferation of endothelial cells (77). VEGF serves as a signal for cyclooxygenase-2 (COX-2)/prostaglandin E2 (PGE2). PGE2 is involved in the major process of COX-2 acting on malignant cells (78). AS-IV inhibits the growth of SGC7901 cells with the downregulation of COX-2, which leads to the suppression of its downstream product, PGE2 expression, and the downregulation of VEGF, thereby decreasing tumor growth (79). Apart from SGC7901, a reduction in VEGF expression has also been reported in studies using A549 and U251 cells.

MDR and increase in chemosensitivity. MDR is the leading cause of the failure of chemotherapy and cancer renascence. The key to reversing tumor drug resistance is to prevent MDR pathways to reduce drug efflux, which can enhance the chemosensitivity of tumor cells (80). It has been found that MDR can be attributed to several factors, including P-gps, lung resistance-related proteins (LRPs), breast cancer resistance protein (BCRP) and multidrug resistance-associated protein 2 (MRP2), all of which can pump drugs out from tumor cells and reduce the anticancer efficacy of drugs (81). Several studies have reported that AS-IV can reverse MDR and increase the chemosensitivity or radiosensitivity of tumors (17,82-87) (Fig. 4)

Caveolin-1 (CAV-1) is a constituent protein playing a role in signal transduction and other cellular activities. It has been confirmed that the expression of CAV-1 is positively associated with cancer metastasis and has, therefore, been identified as a potential target to reverse MDR (88). Zheng et al reported that AS-IV reduced CAV-1 expression and reversed the Taxol-induced increase in CAV-1 expression; furthermore, 


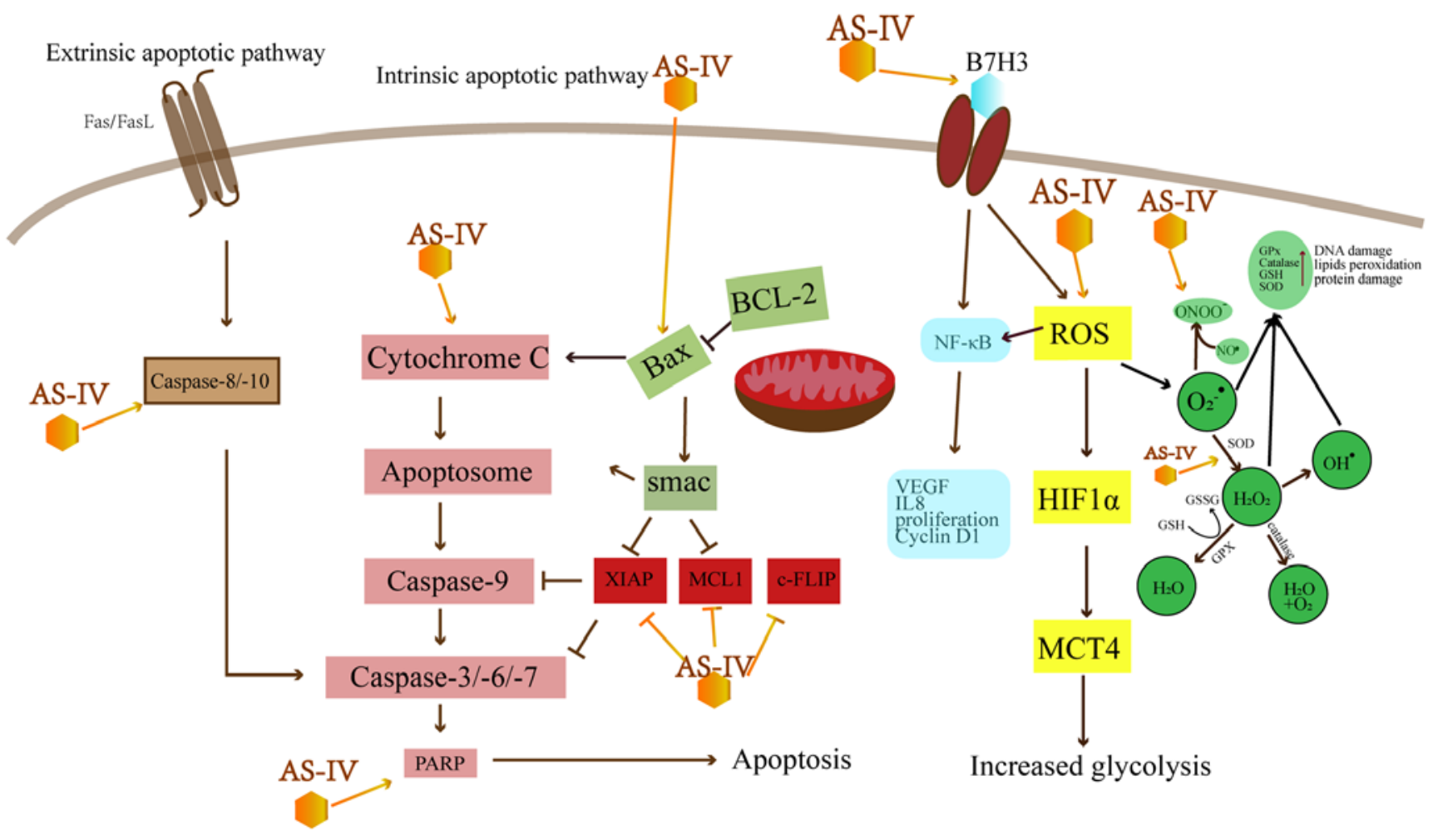

Figure 2. Effect of AS-IV on apoptosis-related pathways. AS-IV, astragaloside IV; XIAP, x-linked mammalian inhibitor of apoptosis; MCL1, myeloid cell leukemia 1; c-FLIP, cellular FLICE-like inhibitory protein; ROS, reactive oxygen species; VEGF, vascular endothelial growth factor; MCT, monocarboxylic acid transporter; HIF, hypoxia-inducing factor; GPx, glutathione peroxidase; GSH, glutathione; SOD, superoxide dismutase.

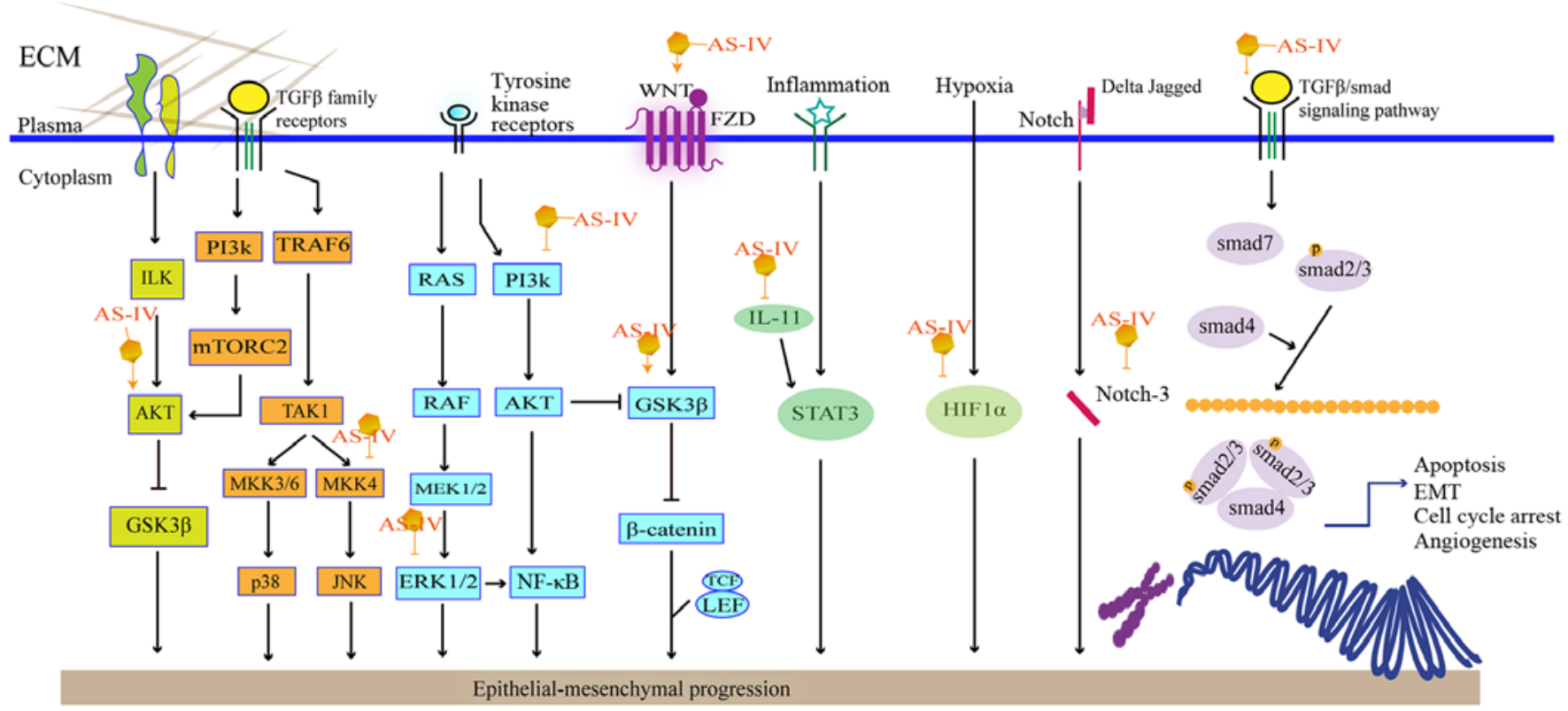

Figure 3. Effect of AS-IV on EMT-related pathways. AS-IV, astragaloside IV; GSK3 $\beta$, glycogen synthase kinase 3 $\beta$; mTOR, mammalian target of rapamycin; HIF, hypoxia-inducing factor.

AS-IV administration resulted in initiating the endothelial nitric oxide synthase (eNOS)/nitric oxide (NO)/peroxynitrite $\left(\mathrm{ONOO}^{-}\right)$pathway and inhibiting $\mathrm{CAV}-1$, which can induce severe oxidative stress and apoptosis (17).

Moreover, the MAPK pathway, which comprises the ERK, JNK and p38 pathways, controls several biological and cellular processes in cancer. Therefore, its activation is vital to
MDR (89). Co-treatment with AS-IV and Taxol lowers ERK and JNK in malignant cells, which are associated with chemosensitizing effects (17).

Studies have found that inhibiting the JNK signaling pathway suppresses the expression of c-Jun and drug-resistant genes, e.g., MDR1 and P-gp, and increases drug-induced the apoptosis of tumor cells. Wang et al demonstrated that AS-IV 


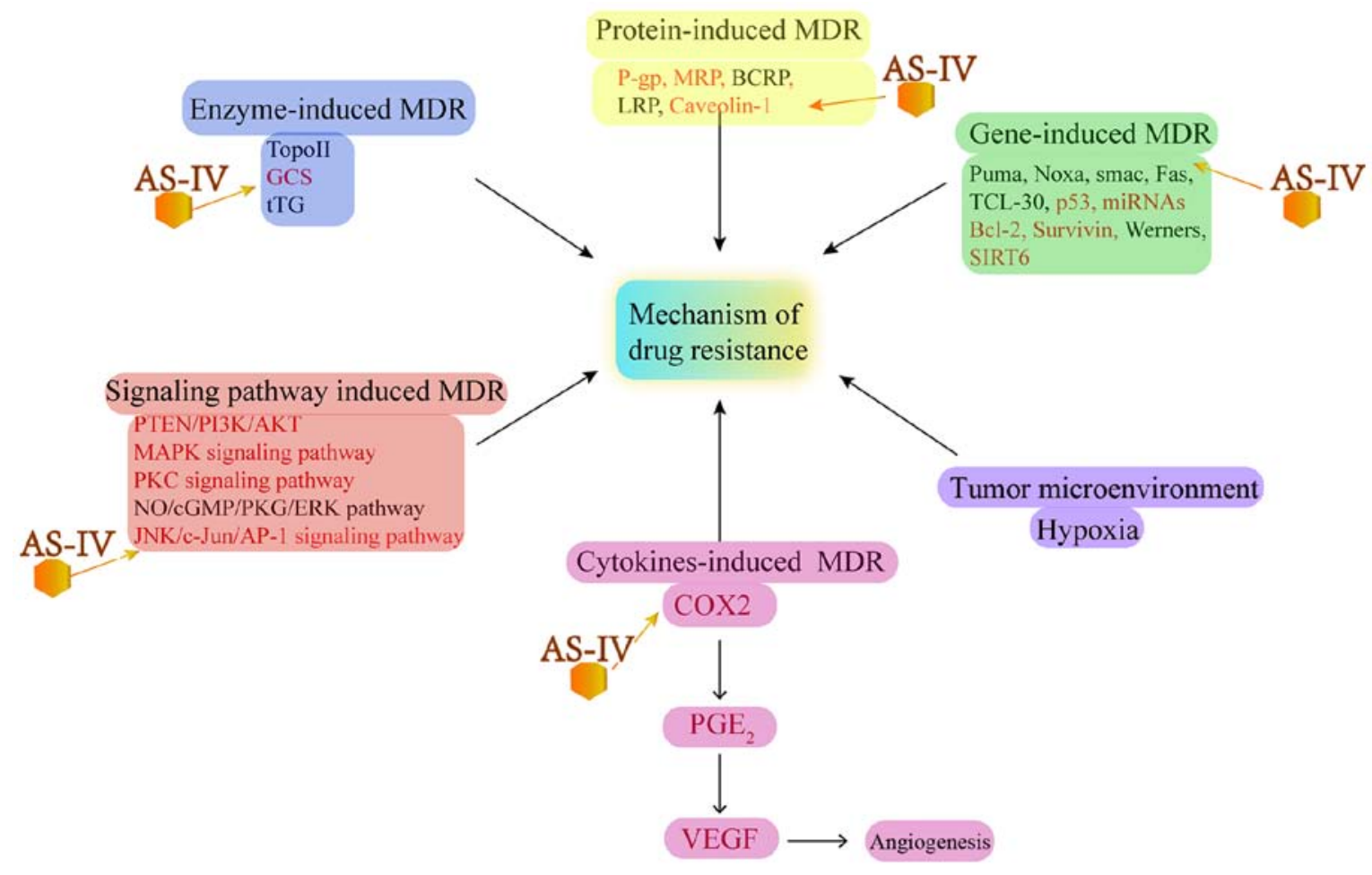

Figure 4. Effect of AS-IV on MDR-related molecular mechanisms. MDR, multidrug resistance; GCS, glucosylceramide synthase; P-gp, P-glycoprotein; LRP, lung resistance-related proteins; BCRP, breast cancer resistance protein; MRP, multidrug resistance-associated protein; COX2, cyclooxygenase 2; PGE2, prostaglandin E2; VEGF, vascular endothelial growth factor; SIRT6, sirtuin 6.

may reverse MDR by inhibiting the JNK/c-Jun/AP-1 pathway in Bel-7402/FU cells $(82,83)$.

Silent information regulator 6 (SIRT6), an NAD ${ }^{+}$-dependent deacetylase, plays a key regulatory role in genomic stability, metabolism, chromatin regulation, telomere integrity, gene transcription and glucose and lipid metabolism. Further exploration of these molecular mechanisms has indicated that the multiple roles of SIRT6 in tumorigenesis are realized by regulating the ERK, SMAD and Raf pathways (84).

SIRT6 also triggers lethal autophagy in human cancer cells (90). Recent studies have reported that the upregulation of SIRT6 enhances the sensitivity of NSCLC cells to other drugs and treatment modalities (91-93). Accordingly, the study by Dai et al illustrated that AS-IV acted on SIRT6 to heighten the tumor responses to gefitinib in the NCI-H1299, HCC827 and A549 lung cancer cell lines (85).

Studies have indicated that NOTCH3 is highly expressed in tumor cells. It also has been shown that the depletion of NOTCH3 by sorafenib and adriamycin can increase the expression of $\mathrm{p} 53$, promote GSK $3 \beta$ phosphorylation and downregulate $\mathrm{p} 21$, thereby enhancing the efficacy of chemotherapy $(94,95)$. In addition, NOTCH3 may be used as a biomarker for RC. In a previous in vitro study, AS-IV was reported to enhance the chemosensitivity of CRC towards cisplatin by suppressing NOTCH3 (86).

The glucosylceramide synthase (GCS)-mediated abolishment of ceramide-induced apoptosis is one of the underlying mechanisms of acquired drug resistance in some resistant cells (96). AS-IV can reverse drug resistance to doxorubicin in HepG2/GCS cells, suggesting that MDR can be prevented using AS-IV as it reduces the expression of GCS (87).
Improvement of immunity. Owing to their high cytotoxicity and proliferation ability, cytotoxic T lymphocytes (CTLs) are useful in the monitoring and elimination of cancer cells. During tumor progression, the tumor microenvironment (TME) results in the suppression of immune function, which results in a loss of the functions of CTL, leading to immune escape.

Tumor-associated macrophages (TAMs) constitute the most important inflammatory cell group in the TME. Recent studies have revealed that TAM may polarize to the M2-type in terms of phenotypic characteristics. Macrophage colony-stimulating factor-1 (CSF-1), interleukin (IL)-4, IL-10, TGF- $\beta$ and IL-13 benefit M2 subgroup differentiation. Moreover, M2 and Tregs can reduce the levels of CTLs. Type 2 (M2) macrophages do not exert antitumor effects, but rather participate in the occurrence, development, invasion and metastasis of tumors; therefore, the phenotype M2 is a novel potential target for tumor therapy (97).

There are multiple mechanisms by virtue of which tumor cells escape recognition by CTLs. Indoleamine-2,3dioxygenase (IDO) is a tryptophan-degrading enzyme that participates in the immune-escape program. In C57BL/6 mice bearing Lewis lung carcinoma cells, AS-IV was shown to exert antineoplastic and immunity-boosting effects to inhibit Tregs and augment CTL activity by suppressing IDO expression (98). AS-IV has also been shown to partially block M2 differentiation via the AMPK signaling pathway, thereby inhibiting invasion, migration and angiogenesis (99).

In 7,12-dimethylbenzanthracene-induced liver and breast cancer in tumor-bearing mice, the effect of co-treatment of cisplatin and AS-IV against breast cancer in vivo was more 
prominent than that of cisplatin alone. The mechanism of action may be related to the effective upregulation of the levels of immune factors IL- $2, \mathrm{IFN}-\gamma, \mathrm{CD}^{+}, \mathrm{CD}^{+}, \mathrm{CD}^{+} / \mathrm{CD}^{+}$, and the downregulation of IL-1, IL- 6 , TNF- $\alpha$ and $\mathrm{CD}^{+}$in liver and breast cancer $(100,101)$.

Moreover, in vivo experiments have demonstrated that AS-IV promotes host immunity by regulating the levels of cytokines, NO and cycle-related mRNA and/or protein expression, particularly IL-1 $\beta$, IL- 6 and TNF- $\alpha$, under the influence of the NF- $\mathrm{B} / \mathrm{MAPK}$ pathway. As an inhibitor of proliferation, AS-IV also modulates the levels of cyclin D1, CDK4 and CDK6 in the host, promotes the secretion of CDs, such as CD40 and CD86, and arrests cells in the G2/M stage (102).

Promotion of autophagy. Autophagy is a process in which proteins or organelles are engulfed into vesicles and fused with lysosomes to form an autophagosome. Subsequently, the enclosed contents are degraded, thus achieving the metabolic needs of cells and the renewal of some organelles (103). Autophagy has a dual-directional effect on the progression and survival of malignant tumors. This progression could be measured based on the distribution of LC3-I and LC3-II, which are biomarkers indicating autophagy vesicle accumulation (104).

AS-IV elevates the level of autophagy-associated proteins, such as LC3I/II, Atg7 and Atg12 in cervical cancer cells. It also mediates differentially expressed proteins, including MGST3, AKR1C2, and ERL1N1, which are related to cancer proliferation and cytoskeleton composition. Two autophagy-related proteins, namely, DCP1A and TMSB4X, have been found to be increased in HeLa and SiHa cells following the administration of AS-IV (105).

The TGF- $\beta /$ SMAD signaling pathway plays a crucial role in a number of types of cancer and the dysfunction of this pathway is an important pathogenic mechanism in cancers. SMAD and downstream TGF- $\beta$ intracellular signaling transfer the ligand-receptor interaction signal from the cytoplasm to the nucleus. In a previous study, in VSCC cells, AS-IV was shown to improve the dysfunctions of the TGF- $\beta /$ SMAD pathway, determined based on the elevated TGF- $\beta$ RII and Smad4 levels; it was also found that AS-IV induced autophagy in SW962 cells, and markedly increased Beclin-1 and LC3-II levels, and decreased p62 protein levels (19).

Prevention of cancer. Aerobic glycolysis and oxidative phosphorylation are common energy sources in tumor cells. Owing to the rapid growth and high energy demand of tumor cells, there is a tendency for an increased glucose uptake and lactate production. Monocarboxylic acid transporters (MCT)1 and MCT4 can transport large amounts of lactic acid produced by tumor cells to the extracellular environment and play a key role in maintaining the acidic environment required for the glycolysis in tumor cells (106). CD147 is indispensable to the activity of MCT1 and MCT4 in gastric cancer. The study by Zhang et al suggested that AS-IV reduced the precancerous lesions of gastric carcinoma (PLGC), inhibited glycolysis by regulating the p53/miRNA-34a/LDHA and p53/TIGAR pathways, and restored the levels of MCT1/4, CD147 and HIF-1 $\alpha$ (107).

AS-IV inhibits the activity of gastric cancer-associated fibroblasts (GCAFs) with an increased miR-214 and decreased
miR-301a expression. AS-IV also inhibits GCAFs from increasing key factors, such as SRY-box2 (SOX2) and NANOG, in inducing pluripotency in somatic cells, decreasing M-CSF expression and increasing TIMP2 expression (108). All these studies demonstrate that AS-IV hinders the development of gastric cancer. This topic is worthy of further exploration in a clinical setting.

Remission of side-effects from chemotherapy. NADPH oxidase (NOX) is a plasma membrane-related enzyme protein family consisting of 7 members of DUOX1-2 and NOX1-5 families. Among the NOXs, NOX2 and NOX 4 are expressed in the heart and are responsible for increasing intracellular ROS levels. Oxidative stress has been identified as a main cause of doxorubicin (DOX)-induced cardiomyopathy (109,110). DOX administration has been shown to increase the levels of NOX2 and NOX4 in animal hearts, thereby increasing ROS-induced cardiomyopathy. By contrast, AS-IV noticeably reduces the cardiomyopathy induced by DOX, decreases the oxidative stress caused by NOX2 and NOX4, attenuates the complications of doxorubicin, and, thus, appears suitable as an adjuvant to chemotherapy (111).

\section{Conclusions and future perspectives}

TCMs are commonly used in clinical treatment in several Asian countries. They significantly contribute towards enhancing the effects of other therapies and reducing toxicity. The in vitro and in vivo effects of AS-IV in inhibiting tumor proliferation and invasion and in promoting tumor cell apoptosis have been well-documented. Current findings highlight the role of AS-IV in suppressing EMT, as EMT plays a role in the majority of processes related to AS-IV in cancer. Furthermore, AS-IV has also been proven to exert significant preventive effects against MDR and in the regulation of immunity in antitumor therapy. In addition, the low-cost and ready availability of AS-IV further accentuates its potential in tumor therapy.

Despite these advantages, the use of AS-IV is still limited by several means: i) Its mechanisms of action have not been adequately elucidated. A previous study demonstrated that AS-IV enhanced the efflux activity of P-gp and BCRP through the Nrf2-ARE signaling pathway, exerting the opposite effect on $\mathrm{P}$-gp protein in liver cancer and gastric cancer cells, which may lead to herb-drug interactions following treatment with AS-IV (112); ii) there are no clinical studies (to the best of our knowledge) available that explore the role and safety of AS-IV in human cancers. The human body is complex compared to model organisms (in vivo or in vitro) used in a laboratory setting; iii) finally, the dose of AS-IV used in studies varies greatly; therefore, the safety window and effective dose of AS-IV need to be accurately established. Thus, further studies are warranted to determine the effects of AS-IV and large cohort clinical studies are required to further validate its efficacy in a clinical setting.

\section{Acknowledgements}

The authors would like to thank the First Teaching Hospital of Tianjin University of Traditional Chinese Medicine for providing the laboratory. 


\section{Funding}

The present study was supported by Tianjin Science \& Technology Plan Projects (no. 17ZXMFSY00190), the Tianjin Traditional Chinese Medicine Research Project, Tianjin health and family planning commission (no. 2017003) and the National Natural Science Foundation of China (no. 81403220).

\section{Availability of data and materials}

Not applicable.

\section{Authors' contributions}

All authors (TC, PY and YJ) were involved in the conception and design of the study. TC was invovled in the drafting of the manuscript and in the processing of the figures. PY and YJ were involved in the critical revision of the manuscript for important intellectual content. YJ was responsible for obtaining funding. TC and PY provided administrative, technical, or material support. PY and YJ supervised and edited the study. All authors have read and approved the final manuscript.

\section{Ethics approval and consent to participate}

Not applicable.

\section{Patient consent for publication}

Not applicable.

\section{Competing interests}

The authors declare that they have no competing interests.

\section{References}

1. Bray F, Ferlay J, Soerjomataram I, Siegel RL, Torre LA and Jemal A: Global cancer statistics 2018: GLOBOCAN estimates of incidence and mortality worldwide for 36 cancers in 185 countries. CA Cancer J Clin 68: 394-424, 2018.

2. Chen J, Ni Y, Sun G, Zhu S, Zhao J, Wang Z, Zhang H, Zhu X, Zhang X, Dai J, et al: Survival outcomes of radical prostatectomy + extended pelvic lymph node dissection and radiotherapy in prostate cancer patients with a risk of lymph node invasion over 5\%: A population-based analysis. Front Oncol 10: 607576, 2020

3. Di Cintio F, Dal Bo M, Baboci L, De Mattia E, Polano M and Toffoli G: The molecular and microenvironmental landscape of glioblastomas: Implications for the novel treatment choices. Front Neurosci 14: 603647, 2020.

4. Li Y, Wang J, Ma X, Tan L, Yan Y, Xue C, Hui B, Liu R, Ma H and Ren $\mathrm{J}$ : A review of neoadjuvant chemoradiotherapy for locally advanced rectal cancer. Int J Biol Sci 12: 1022-1031, 2016.

5. Bhoday J, Glimelius B, Tait D, Glynne-Jones R, Adams R and Brown G: Session 4: What should we do for poor responders after chemoradiotherapy: Bad biology or should the fight go on? Colorectal Dis 20 Suppl 1: 97-99, 2018.

6. Qi F, Zhao L, Zhou A, Zhang B, Li A, Wang Z and Han J: The advantages of using traditional Chinese medicine as an adjunctive therapy in the whole course of cancer treatment instead of only terminal stage of cancer. Biosci Trends 9: 16-34, 2015.

7. Jung Y, Jerng $U$ and Lee S: A systematic review of anticancer effects of radix astragali. Chin J Integr Med 22: 225-236, 2016.

8. Li X, Qu L, Dong Y, Han L, Liu E, Fang S, Zhang Y and Wang T: A review of recent research progress on the astragalus genus. Molecules 19: 18850-18880, 2014.
9. Yu SY, Ouyang HT, Yang JY, Huang XL, Yang T, Duan JP, Cheng JP, Chen YX, Yang YJ and Qiong P: Subchronic toxicity studies of Radix Astragali extract in rats and dogs. J Ethnopharmacol 110: 352-355, 2007.

10. Gui D, Guo Y, Wang F, Liu W, Chen J, Chen Y, Huang J and Wang N: Astragaloside IV, a novel antioxidant, prevents glucose-induced podocyte apoptosis in vitro and in vivo. PLoS One 7: e39824, 2012.

11. Ren S, Zhang H, Mu Y, Sun M and Liu P: Pharmacological effects of Astragaloside IV: A literature review. J Tradit Chin Med 33: 413-416, 2013.

12. Zhao J, Yang P, Li F, Tao L, Ding H, Rui Y, Cao Z and Zhang W: Therapeutic effects of astragaloside IV on myocardial injuries: Multi-target identification and network analysis. PLoS One 7: e44938, 2012.

13. Xu W, Shao X, Tian L, Gu L, Zhang M, Wang Q, Wu B, Wang L, Yao J, Xu X, et al: Astragaloside IV ameliorates renal fibrosis via the inhibition of mitogen-activated protein kinases and antiapoptosis in vivo and in vitro. J Pharmacol Exp Ther 350: 552-562, 2014.

14. Karmakar S, Banik NL, Patel SJ and Ray SK: Curcumin activated both receptor-mediated and mitochondria-mediated proteolytic pathways for apoptosis in human glioblastoma T98G cells. Neurosci Lett 407: 53-58, 2006.

15. Bagci EZ, Vodovotz Y, Billiar TR, Ermentrout GB and Bahar I Bistability in apoptosis: Roles of bax, bcl-2, and mitochondrial permeability transition pores. Biophys J 90: 1546-1559, 2006.

16. Sun P, Liu Y, Wang Q and Zhang B: Astragaloside IV inhibits human colorectal cancer cell growth. Front Biosci (Landmark Ed) 24: 597-606, 2019.

17. Zheng Y, Dai Y, Liu W, Wang N, Cai Y, Wang S, Zhang F, Liu P, Chen Q and Wang Z: Astragaloside IV enhances taxol chemosensitivity of breast cancer via caveolin-1-targeting oxidant damage. J Cell Physiol 234: 4277-4290, 2019.

18. Jia L, Lv D, Zhang S, Wang Z and Zhou B: Astragaloside IV Inhibits the progression of non-small cell lung cancer through the Akt/GSK-3 $\beta / \beta$-Catenin Pathway. Oncol Res 27: 503-508, 2019.

19. Zhao Y, Wang L, Wang Y, Dong S, Yang S, Guan Y and Wu X: Astragaloside IV inhibits cell proliferation in vulvar squamous cell carcinoma through the TGF- $\beta /$ Smad signaling pathway. Dermatol Ther 32: e12802, 2019.

20. Cui X, Jiang X, Wei C, Xing Y and Tong G: Astragaloside IV suppresses development of hepatocellular carcinoma by regulating miR-150-5p/3-catenin axis. Environ Toxicol Pharmacol 78: 103397, 2020.

21. Ying G: Astragaloside induces gastric MGC-803 cells apoptosis by inhibiting AKT and NF-KB pathway. Int J Lab Med 19: 2341-2344, 2018

22. Elmore S: Apoptosis: A review of programmed cell death. Toxicol Pathol 35: 495-516, 2007.

23. Hu T, Fei Z and Wei N: Chemosensitive effects of Astragaloside IV in osteosarcoma cells via induction of apoptosis and regulation of caspase-dependent Fas/FasL signaling. Pharmacol Rep 69: 1159-1164, 2017.

24. Deveraux QL and Reed JC: IAP family proteins-suppressors of apoptosis. Genes Dev 13: 239-252, 1999.

25. Avila MA, Berasain C, Sangro B and Prieto J: New therapies for hepatocellular carcinoma. Oncogene 25: 3866-3884, 2006.

26. Du X, Bao G, He X, Zhao H, Yu F, Qiao Q, Lu J and Ma Q: Expression and biological significance of c-FLIP in human hepatocellular carcinomas. J Exp Clin Cancer Res 28: 24, 2009.

27. Fleischer B, Schulze-Bergkamen H, Schuchmann M, Weber A, Biesterfeld S, Müller M, Krammer PH and Galle PR: Mcl-1 is an anti-apoptotic factor for human hepatocellular carcinoma. Int J Oncol 28: 25-32, 2006.

28. Che Y, Ye F, Xu R, Qing H, Wang X, Yin F, Cui M, Burstein D, Jiang B and Zhang DY: Co-expression of XIAP and cyclin D1 complex correlates with a poor prognosis in patients with hepatocellular carcinoma. Am J Pathol 180: 1798-1807, 2012

29. Cameron BD, Traver G, Roland JT, Brockman AA, Dean D, Johnson L, Boyd K, Ihrie RA and Freeman ML: Bcl2-Expressing Quiescent Type B neural stem cells in the Ventricular-Subventricular zone are resistant to concurrent Temozolomide/X-Irradiation. Stem Cells 37: 1629-1639, 2019.

30. Tanaka N, Patel AA, Wang J, Frederick MJ, Kalu NN, Zhao M, Fitzgerald AL, Xie TX, Silver NL, Caulin C, et al: Wee-1 kinase inhibition sensitizes high-risk HPV+ HNSCC to apoptosis accompanied by downregulation of MCl-1 and XIAP antiapoptotic proteins. Clin Cancer Res 21: 4831-4844, 2015. 
31. Lin YC, Chen RY, Liang JA, Hung YC, Yeh LS, Chang WC, Lin WC, Chang YY and Chen SW: Immunohistochemical biomarkers of survival in patients with adenocarcinoma of the uterine cervix receiving chemoradiotherapy. Anticancer Res 39: 3231-3240, 2019.

32. Finkel T: Oxidant signals and oxidative stress. Curr Opin Cell Biol 15: 247-254, 2003

33. Su CM, Wang HC, Hsu FT, Lu CH, Lai CK, Chung JG and Kuo YC: Astragaloside IV induces apoptosis, $\mathrm{G}_{1}$-phase arrest and inhibits anti-apoptotic signaling in hepatocellular carcinoma. In Vivo 34: 631-638, 2020.

34. Chang XY: Effects of cisplatin combined with astragaloside iv on apoptosis genes in C6 glioma mice. Chin J Gerontol 13: 3282-3284, 2019 (In Chinese).

35. Moloney JN and Cotter TG: ROS signalling in the biology of cancer. Semin Cell Dev Biol 80: 50-64, 2018.

36. Bułdak RJ, Bułdak Ł, Kukla M, Gabriel A and ZwirskaKorczala K: Significance of selected antioxidant enzymes in cancer cell progression. Pol J Pathol 65: 167-175, 2014.

37. Yang JY: Effect of astragaloside IV on the proliferation of Spc-A-1 cells in human lung cancer and its mechanism. Chin Traditional Patent Med 8: 1818-1820, 2016 (In Chinese).

38. Wang L, Kang FB and Shan BE: B7-H3-mediated tumor immunology: Friend or foe? Int J Cancer 134: 2764-2771, 2014.

39. Flem-Karlsen K, Fodstad $\varnothing$, Tan $M$ and Nunes-Xavier CE: B7-H3 in cancer - beyond immune regulation. Trends Cancer 4: 401-404, 2018

40. Ling V, Wu PW, Spaulding V, Kieleczawa J, Luxenberg D, Carreno BM and Collins M: Duplication of primate and rodent B7-H3 immunoglobulin V- and C-like domains: Divergent history of functional redundancy and exon loss. Genomics 82 : 365-377, 2003

41. Wang S, Mou J, Cui L, Wang X and Zhang Z: Astragaloside IV inhibits cell proliferation of colorectal cancer cell lines through down-regulation of B7-H3. Biomed Pharmacother 102: 1037-1044, 2018.

42. He CS, Liu YC, Xu ZP, Dai PC, Chen XW and Jin DH: Astragaloside IV enhances cisplatin chemosensitivity in non-small cell lung cancer cells through inhibition of B7-H3. Cell Physiol Biochem 40: 1221-1229, 2016.

43. An XC: Mechanism of astragaloside IV promoting proliferation and apoptosis of hepatoma cells by inhibiting ROS/NF- $\mathrm{KB}$ signaling pathway. Mod Dig Intervent 12: 1399-1403, 2019 (In Chinese)

44. Brooks PC, Strömblad S, Sanders LC, von Schalscha TL, Aimes RT, Stetler-Stevenson WG, Quigley JP and Cheresh DA: Localization of matrix metalloproteinase MMP-2 to the surface of invasive cells by interaction with integrin alpha $\mathrm{v}$ beta 3 . Cell 85: 683-693, 1996.

45. Trepat $\mathrm{X}$, Chen $\mathrm{Z}$ and Jacobson K: Cell migration. Compr Physiol 2: 2369-2392, 2012.

46. Zhou L, Wang DS, Li QJ, Sun W, Zhang Y and Dou KF: Downregulation of the Notch signaling pathway inhibits hepatocellular carcinoma cell invasion by inactivation of matrix metalloproteinase- 2 and -9 and vascular endothelial growth factor. Oncol Rep 28: 874-882, 2012.

47. Asati V, Mahapatra DK and Bharti SK: PI3K/Akt/mTOR and Ras/Raf/MEK/ERK signaling pathways inhibitors as anticancer agents: Structural and pharmacological perspectives. Eur J Med Chem 109: 314-341, 2016

48. Rizzo D, Ruggiero A, Amato M, Maurizi P and Riccardi R: BRAF and MEK inhibitors in pediatric glioma: New therapeutic strategies, new toxicities. Expert Opin Drug Metab Toxicol 12: $1397-1405,2016$

49. Zohrabian VM, Forzani B, Chau Z, Murali R and Jhanwar-Uniyal M: Rho/ROCK and MAPK signaling pathways are involved in glioblastoma cell migration and proliferation. Anticancer Res 29: 119-123, 2009.

50. Nickl-Jockschat T, Arslan F, Doerfelt A, Bogdahn U, Bosserhoff A and Hau P: An imbalance between Smad and MAPK pathways is responsible for TGF-beta tumor promoting effects in high-grade gliomas. Int J Oncol 30: 499-507, 2007.

51. Wu QN, Liao YF, Lu YX, Wang Y, Lu JH, Zeng ZL, Huang QT, Sheng H, Yun JP, Xie D, et al: Pharmacological inhibition of DUSP6 suppresses gastric cancer growth and metastasis and overcomes cisplatin resistance. Cancer Lett 412: 243-255, 2018.

52. Jiang X,Zhu X, Huang W, Xu H,Zhao Z, Li S, Li S, Cai J and Cao J: Garlic-derived organosulfur compound exerts antitumor efficacy via activation of MAPK pathway and modulation of cytokines in SGC-7901 tumor-bearing mice. Int Immunopharmacol 48: $135-145,2017$
53. Li B, Wang F, Liu N, Shen W and Huang T: Astragaloside IV inhibits progression of glioma via blocking MAPK/ERK signaling pathway. Biochem Biophys Res Commun 491: 98-103, 2017.

54. Cao Y: The anti-invasion effects of astragaloside IV on gastric cancer cell line SGC7901 and its related mechanism. Shanxi Med J 6: 656-659, 2015 (In Chinese).

55. Wu JY: Inhibition and mechanism of astragaloside IV on $\mathrm{H} 22$ ascites in BALB/C mice. Chin J Pharmacovigilance 3: 138-142, 2016 (In Chinese)

56. Ogata Y, Miura K, Ohkita A, Nagase H and Shirouzu K: Imbalance between matrix metalloproteinase 9 and tissue inhibitor of metalloproteinases 1 expression by tumor cells implicated in liver metastasis from colorectal carcinoma. Kurume Med J 48 211-218, 2001.

57. Hajitou A, Sounni NE, Devy L, Grignet-Debrus C, Lewalle JM, Li H, Deroanne CF, Lu H, Colige A, Nusgens BV, et al: Down-regulation of vascular endothelial growth factor by tissue inhibitor of metalloproteinase-2: Effect on in vivo mammary tumor growth and angiogenesis. Cancer Res 61: 3450-3457, 2001.

58. Keshavarz-Pakseresht B, Shandiz SA and Baghbani-Arani F: Imatinib induces up-regulation of NM23, a metastasis suppressor gene, in human Hepatocarcinoma (HepG2) cell line. Gastroenterol Hepatol Bed Bench 10: 29-33, 2017.

59. Zhou K: Effects of astragaloside IV on gastric cancer cells and its related mechanisms. Hebei Medical University, 2016.

60. Du B and Shim JS: Targeting epithelial-mesenchymal transition (EMT) to overcome drug resistance in cancer. Molecules 21: 965 , 2016.

61. Han J, Shen X, Zhang Y, Wang S and Zhou L: Astragaloside IV suppresses transforming growth factor- $\beta 1$-induced epithelial-mesenchymal transition through inhibition of Wnt/ $\beta$-catenin pathway in glioma U251 cells. Biosci Biotechnol Biochem 84: $1345-1352,2020$

62. Larue L and Bellacosa A: Epithelial-mesenchymal transition in development and cancer: Role of phosphatidylinositol 3 kinase/AKT pathways. Oncogene 24: 7443-7454, 2005.

63. Qin CD, Ma DN, Ren ZG, Zhu XD, Wang CH, Wang YC, Ye BG, Cao MQ, Gao DM and Tang ZY: Astragaloside IV inhibits metastasis in hepatoma cells through the suppression of epithelial-mesenchymal transition via the Akt/GSK-3// $\beta$-catenin pathway. Oncol Rep 37: 1725-1735, 2017.

64. Zhang L, Zhou J, Qin X, Huang H and Nie C: Astragaloside IV inhibits the invasion and metastasis of SiHa cervical cancer cells via the TGF- $\beta 1$-mediated PI3K and MAPK pathways. Oncol Rep 41: 2975-2986, 2019.

65. Cheng X, Gu J, Zhang M, Yuan J, Zhao B, Jiang J and Jia X: Astragaloside IV inhibits migration and invasion in human lung cancer A549 cells via regulating PKC- $\alpha$-ERK1/2-NF- $\kappa \mathrm{B}$ pathway. Int Immunopharmacol 23: 304-313, 2014.

66. Su CC, Chiou TL, Chan MH and Lin JG: Astragaloside IV increases MMP-2 mRNA and protein expression in human lung cancer A549 cells. Mol Med Rep 2: 107-113, 2009.

67. Liu YN, Yin JJ, Abou-Kheir W, Hynes PG, Casey OM, Fang L, Yi M, Stephens RM, Seng V, Sheppard-Tillman H, et al: MiR-1 and miR-200 inhibit EMT via Slug-dependent and tumorigenesis via Slug-independent mechanisms. Oncogene 32: 296-306, 2013.

68. Kitamura K, Seike M, Okano T, Matsuda K, Miyanaga A, Mizutani H, Noro R, Minegishi Y, Kubota K and Gemma A: MiR-134/487b/655 cluster regulates TGF- $\beta$-induced epithelial-mesenchymal transition and drug resistance to gefitinib by targeting MAGI2 in lung adenocarcinoma cells. Mol Cancer Ther 13: 444-453, 2014.

69. Liu Y, Zhang M, Qian J, Bao M, Meng X, Zhang S, Zhang L, Zhao R, Li S, Cao Q, et al: miR-134 functions as a tumor suppressor in cell proliferation and epithelial-to-mesenchymal Transition by targeting KRAS in renal cell carcinoma cells. DNA Cell Biol 34: 429-436, 2015.

70. Ye Q, Su L, Chen D, Zheng W and Liu Y: Astragaloside IV Induced miR-134 expression reduces EMT and increases chemotherapeutic sensitivity by suppressing CREB1 signaling in colorectal cancer cell line SW-480. Cell Physiol Biochem 43: 1617-1626, 2017.

71. Lin A, Hu Q, Li C, Xing Z, Ma G, Wang C, Li J, Ye Y, Yao J, Liang K, et al: The LINK-A lncRNA interacts with PtdIns $(3,4,5)$ $\mathrm{P}_{3}$ to hyperactivate AKT and confer resistance to AKT inhibitors. Nat Cell Biol 19: 238-251, 2017.

72. Yan X, Hu Z, Feng Y, Hu X, Yuan J, Zhao SD, Zhang Y, Yang L, Shan W, He Q, et al: Comprehensive genomic characterization of long non-coding RNAs across human cancers. Cancer Cell 28: 529-540, 2015 
73. Yuan JH, Yang F, Wang F, Ma JZ, Guo YJ, Tao QF, Liu F, Pan W, Wang TT, Zhou CC, et al: A long noncoding RNA activated by TGF-beta promotes the invasion-metastasis cascade in hepatocellular carcinoma. Cancer Cell 25: 666-681, 2014.

74. Li Y, Ye Y and Chen H: Astragaloside IV inhibits cell migration and viability of hepatocellular carcinoma cells via suppressing long noncoding RNA ATB. Biomed Pharmacother 99: 134-141, 2018.

75. Jiang K, Lu Q, Li Q, Ji Y, Chen W and Xue X: Astragaloside IV inhibits breast cancer cell invasion by suppressing Vav3 mediated Rac1/MAPK signaling. Int Immunopharmacol 42 : 195-202, 2017

76. Qi H, Wei L, Han Y, Zhang Q, Lau AS and Rong J: Proteomic characterization of the cellular response to chemopreventive triterpenoid astragaloside IV in human hepatocellular carcinoma cell line HepG2. Int J Oncol 36: 725-735, 2010.

77. Apte RS, Chen DS and Ferrara N: VEGF in signaling and disease: Beyond discovery and development. Cell 176: 1248-1264, 2019.

78. Hashemi Goradel N, Najafi M, Salehi E, Farhood B and Mortezaee K: Cyclooxygenase-2 in cancer: A review. J Cell Physiol 234: 5683-5699, 2019.

79. Cao LP: Effect of astragaloside and $\beta$-elemene on expression of COX-2 and $\mathrm{PGE}_{2}$ in gastric cancer cell line SGC7901. Mod J Integr Tradit Chin West Med 7: 798-800, 2010 (In Chinese).

80. Li YJ, Lei YH, Yao N, Wang CR, Hu N, Ye WC, Zhang DM and Chen ZS: Autophagy and multidrug resistance in cancer. Chin J Cancer 36: 52, 2017.

81. Choi $\mathrm{YH}$ and $\mathrm{Yu} \mathrm{AM}: \mathrm{ABC}$ transporters in multidrug resistance and pharmacokinetics, and strategies for drug development Curr Pharm Des 20: 793-807, 2014

82. Wang PP, Luan JJ, Xu WK, Wang L, Xu DJ, Yang CY, Zhu YH and Wang YQ: Astragaloside IV downregulates the expression of MDR1 in Bel-7402/FU human hepatic cancer cells by inhibiting the JNK/c-Jun/AP-1 signaling pathway. Mol Med Rep 16: 2761-2766, 2017.

83. Wang PP, Xu DJ, Huang C, Wang WP and Xu WK: Astragaloside IV reduces the expression level of P-glycoprotein in multidrug-resistant human hepatic cancer cell lines. Mol Med Rep 9: 2131-2137, 2014.

84. Sebastián C, Zwaans BM, Silberman DM, Gymrek M, Goren A, Zhong L, Ram O, Truelove J, Guimaraes AR, Toiber D, et al The histone deacetylase SIRT6 is a tumor suppressor that controls cancer metabolism. Cell 151: 1185-1199, 2012.

85. Dai PC, Liu DL, Zhang L, Ye J, Wang Q, Zhang HW, Lin XH and Lai GX: Astragaloside IV sensitizes non-small cell lung cancer cells to gefitinib potentially via regulation of SIRT6. Tumour Biol 39: 1010428317697555, 2017.

86. Xie T, Li Y, Li SL and Luo HF: Astragaloside IV enhances cisplatin chemosensitivity in human colorectal cancer via regulating NOTCH3. Oncol Res 24: 447-453, 2016.

87. Tian YZ: The function and mechanism of astragaloside IV on the chemoresistance of HepG2/GCS cell lines. Chin J Hepatobiliary Surg 8: 555-559, 2018 (In Chinese).

88. Wang Z, Wang N, Liu P, Peng F, Tang H, Chen Q, Xu R, Dai Y, Lin Y, Xie X, et al: Caveolin-1, a stress-related oncotarget, in drug resistance. Oncotarget 6: 37135-37150, 2015.

89. Morrison DK: MAP kinase pathways. Cold Spring Harb Perspect Biol 4: a011254, 2012.

90. Iachettini S, Trisciuoglio D, Rotili D, Lucidi A, Salvati E, Zizza P, Di Leo L, Del Bufalo D, Ciriolo MR, Leonetti C, et al: Pharmacological activation of SIRT6 triggers lethal autophagy in human cancer cells. Cell Death Dis 9: 996, 2018.

91. Shang JL, Ning SB, Chen YY, Chen TX and Zhang J: MDL-800, an allosteric activator of SIRT6, suppresses proliferation and enhances EGFR-TKIs therapy in non-small cell lung cancer. Acta Pharmacol Sin 42: 120-131, 2021.

92. Krishnamoorthy V and Vilwanathan R: Silencing Sirtuin 6 induces cell cycle arrest and apoptosis in non-small cell lung cancer cell lines. Genomics 112: 3703-3712, 2020.

93. Wang J, Cai Y and Sheng Z: Experimental studies on the protective effects of the overexpression of lentivirus-mediated sirtuin 6 on radiation-induced lung injury. Adv Clin Exp Med 29: 873-877, 2020.

94. Giovannini C, Baglioni M, Baron Toaldo M, Ventrucci C, D'Adamo S, Cipone M, Chieco P, Gramantieri L and Bolondi L: Notch3 inhibition enhances sorafenib cytotoxic efficacy by promoting GSK3b phosphorylation and p21 down-regulation in hepatocellular carcinoma. Oncotarget 4: 1618-1631, 2013.
95. Giovannini C, Gramantieri L, Chieco P, Minguzzi M, Lago F, Pianetti S, Ramazzotti E, Marcu KB and Bolondi L: Selective ablation of Notch3 in HCC enhances doxorubicin's death promoting effect by a p53 dependent mechanism. J Hepatol 50: 969-979, 2009.

96. Liu YY, Hill RA and Li YT: Ceramide glycosylation catalyzed by glucosylceramide synthase and cancer drug resistance. Adv Cancer Res 117: 59-89, 2013

97. Farhood B, Najafi M and Mortezaee K: CD8(+) cytotoxic T lymphocytes in cancer immunotherapy: A review. J Cell Physiol 234: 8509-8521, 2019.

98.Zhang A, Zheng Y, Que Z, Zhang L, Lin S, Le V, Liu J and Tian J: Astragaloside IV inhibits progression of lung cancer by mediating immune function of Tregs and CTLs by interfering with IDO. J Cancer Res Clin Oncol 140: 1883-1890, 2014.

99. Xu F, Cui WQ, Wei Y, Cui J, Qiu J, Hu LL, Gong WY, Dong JC and Liu BJ: Astragaloside IV inhibits lung cancer progression and metastasis by modulating macrophage polarization through AMPK signaling. J Exp Clin Cancer Res 37: 207, 2018.

100. Liu TG: Effects of cisplatin combined with astragaloside IV on inflammatory factors and immune function in rats with breast cancer. Chin J Gerontol 4: 863-865, 2020 (In Chinese).

101. Lin L: The antitumor effect ASIV and $\beta$-elemene to the immune system of mice with liver tumor. Nanjing University of Chinese Medicine, 2011.

102. Li Y, Meng T, Hao N, Tao H, Zou S, Li M, Ming P, Ding H, Dong J, Feng S, et al: Immune regulation mechanism of Astragaloside IV on RAW264.7 cells through activating the NF- $\kappa$ B/MAPK signaling pathway. Int Immunopharmacol 49: 38-49, 2017.

103. Singh SS, Vats S, Chia AY, Tan TZ, Deng S, Ong MS, Arfuso F, Yap CT, Goh BC, Sethi G, et al: Dual role of autophagy in hallmarks of cancer. Oncogene 37: 1142-1158, 2018.

104. Tanida I, Ueno T and Kominami E: LC3 and Autophagy. Methods Mol Biol 445: 77-88, 2008.

105. Xia C, He Z and Cai Y: Quantitative proteomics analysis of differentially expressed proteins induced by astragaloside IV in cervical cancer cell invasion. Cell Mol Biol Lett 25: 25, 2020.

106. Hong CS, Graham NA, Gu W, Espindola Camacho C, Mah V, Maresh EL, Alavi M, Bagryanova L, Krotee PAL, Gardner BK, et al: MCT1 modulates cancer cell pyruvate export and growth of tumors that co-express MCT1 and MCT4. Cell Rep 14: 1590-1601, 2016.

107. Zhang C, Cai T, Zeng X, Cai D, Chen Y, Huang X, Gan H, Zhuo J, Zhao Z, Pan H and Li S: Astragaloside IV reverses MNNG-induced precancerous lesions of gastric carcinoma in rats: Regulation on glycolysis through miRNA-34a/LDHA pathway. Phytother Res 32: 1364-1372, 2018.

108. Wang ZF, Ma DG, Zhu Z, Mu YP, Yang YY, Feng L, Yang H, Liang JQ, Liu YY, Liu L and Lu HW: Astragaloside IV inhibits pathological functions of gastric cancer-associated fibroblasts. World J Gastroenterol 23: 8512-8525, 2017.

109. Lou H, Kaur K, Sharma AK and Singal PK: Adriamycin-induced oxidative stress, activation of MAP kinases and apoptosis in isolated cardiomyocytes. Pathophysiology 13: 103-109, 2006.

110. Cave A: Selective targeting of NADPH oxidase for cardiovascular protection. Curr Opin Pharmacol 9: 208-213, 2009.

111. Lin J, Fang L, Li H, Li Z, Lyu L, Wang H and Xiao J: Astragaloside IV alleviates doxorubicin induced cardiomyopathy by inhibiting NADPH oxidase derived oxidative stress. Eur J Pharmacol 859: 172490, 2019.

112. Lou Y, Guo Z, Zhu Y, Zhang G, Wang Y, Qi X, Lu L, Liu Z and $\mathrm{Wu} \mathrm{J}$ : Astragali radix and its main bioactive compounds activate the Nrf2-mediated signaling pathway to induce P-glycoprotein and breast cancer resistance protein. J Ethnopharmacol 228: 82-91, 2019.

113. Zhu J and Wen K: Astragaloside IV inhibits TGF- $\beta 1$-induced epithelial-mesenchymal transition through inhibition of the $\mathrm{PI} 3 \mathrm{~K} / \mathrm{Akt} / \mathrm{NF}-\mathrm{\kappa B}$ pathway in gastric cancer cells. Phytother Res 32: 1289-1296, 2018.

114. Zhang G, Ou R, Li F, Wu J, Zheng L, Tong Y, Liu Y, Liu Z and $\mathrm{Lu} \mathrm{L}$ : Regulation of drug-metabolizing enzymes and efflux transporters by Astragali radix decoction and its main bioactive compounds: Implication for clinical drug-drug interactions. J Ethnopharmacol 180: 104-113, 2016. 